\section{Raynaud's Phenomenon as a Presenting Feature of Hypothyroidism in an 11-year-old Girl}

\section{To the Editor:}

Raynaud's phenomenon (RP) is manifested clinically by sharply demarcated triphasic color changes to the skin of the digits or extremities, typically precipitated by cold exposure or physical or emotional stress. It is considered primary if it occurs in the absence of any underlying disease and secondary if found in association with a structural vascular disease such as a connective tissue disorder. In a multicenter observational study of 761 patients with RP, $65 \%$ of patients with RP had a secondary condition, with over $50 \%$ having a connective tissue disease; only 2 patients $(0.3 \%)$ were found to have associated hypothyroidism ${ }^{1}$. A causal relationship between thyroid deficiency and RP has been reported in a number of adult patients ${ }^{2-6}$. We describe an 11-year-old patient with severe undiagnosed primary hypothyroidism presenting with RP.

An 11-year-old girl was referred with a history of increasingly cold hands and feet for about 2 years. She described no pain but significant color changes affecting all fingers. Her parents also reported that she had had low energy levels, and had become notably inactive and lethargic over the previous 12 months. She had no history of fever or rash. She had been previously investigated for nasal speech and had attended speech and language therapy. Her parents had noted that her growth was delayed in comparison to her peers.

On examination, her height was less than third centile and weight was on the tenth centile for her age. There was evidence of mild dysmorphic features including hypertelorism and a thin, long, flat philtrim with a thin upper lip. She had a flattened nasal bridge with a prominent nose. She had evidence of hirsutism. Her peripheries were cool on examination. She had dry scaling and a purplish discoloration of the tips of her toes. She had prominent dilated loops of her nailfold capillaries on capillaroscopy, although the vessels were not found to be tortuous. Mucosal and conjunctival examinations were normal. Assessment of her musculoskeletal system showed stiff end range of movement of most joints, in particular both subtalars and elbows. She had early breast bud development but no evidence of pubarche. She had a prominent distended abdomen with a palpable liver approximately $2 \mathrm{~cm}$ below the costal margin. The rest of her physical examination was within normal limits.

Investigations revealed normal urea and electrolytes, hemoglobin 96 $\mathrm{g} / \mathrm{l}$, platelet count $148 \times 10^{9} / 1$, white blood cell count $3.2 \times 10^{9} / 1$, and erythrocyte sedimentation rate $25 \mathrm{~mm} / \mathrm{h}$. Thyroid-stimulating hormone was $1035 \mathrm{mIU} / \mathrm{l}$ (range 0.1-5.0) and a free T4 $<3.9 \mathrm{pmol} / \mathrm{l}$ (range 10-22). Her autoimmune and metabolic laboratory tests were negative. Creatinine kinase was elevated at $478 \mathrm{U} / \mathrm{l}$ (range 30-220). Plasma estradiol concentration was markedly reduced at $22 \mathrm{pmol} / \mathrm{l}$. Chromosomal analysis was normal. Her bone age was delayed at 8 years of age, which may indicate that the hypothyroidism was present for a number of years.

She was started on L-thyroxine therapy, and on followup 3 weeks later was noted to have resolution of her cool peripheries and overall improved energy. Within 12 weeks of treatment she had grown $5.1 \mathrm{~cm}$.

Classification of RP has traditionally been defined as "primary" or "secondary." In the secondary forms of RP, it is thought that the underlying vascular disease disrupts the normal complex regulation of regional blood flow to the digits and skin. Clinical conditions that can be associated with
$\mathrm{RP}$ are extensive and include systemic sclerosis, systemic lupus erythematosus, and other connective tissue diseases.

The first reported case of RP associated with hypothyroidism was in 1976; Shagan and Friedman described 2 patients with RP and hypothyroidism whose symptoms disappeared with thyroid replacement therapy ${ }^{2}$. Two further case reports described adult patients who had had RP for years and were found to be hypothyroid ${ }^{3,4}$. One of these patients, a 29-year-old woman, had an acute inferior myocardial infarction with normal coronary arteries $^{3}$. With the replacement of thyroid hormone, symptoms from both the hypothyroidism and RP promptly disappeared. RP has also been found to be associated with hypothyroidism due to panhypopituarism, as described in 2 further case reports ${ }^{5,6}$. There is a paucity of information on whether the association of hypothyroidism and RP occurs in the pediatric population.

It is believed that the pathogenesis of RP lies in the reduced digital blood flow due to excessive vasoconstriction. This is likely caused by hyperactivity of the sympathetic nervous system or by exaggerated sensitivity of the digital arterioles to the local vasoconstricting factors. The mechanism linking RP and hypothyroidism has been studied in 2 adult patients. Vascular studies in one patient demonstrated decreased vasomotor tone after thyroid replacement therapy ${ }^{2}$. It is still not clear, however, whether the association of hypothyroidism and RP is a direct hormonal influence or an indirect immune process. The remission of RP in patients after thyroid replacement therapy seems to indicate the causal role of thyroid deficiency in giving rise to $\mathrm{RP}^{2,4,5}$.

This is the first case report describing the association of hypothyroidism and RP in a pediatric patient. The pathogenesis linking these 2 clinical entities needs to be further elucidated.

MICHELLE BATTHISH, MD, Department of Paediatrics, The Hospital for Sick Children, Toronto, Ontario, Canada; COLM COSTIGAN, MD, Department of Paediatric Endocrinology; ORLA G. KILLEEN, MD, Department of Rheumatology, Our Lady's Hospital for Sick Children, Crumlin, Dublin 12, Ireland. Address reprint requests to Dr. Killeen; E-mail: orla.killeen@olchc.ie

\section{REFERENCES}

1. Grassi W, De Angelis R, Lapadula G, Leardini G, Scarpa R. Clinical diagnosis found in patients with Raynaud's phenomenon: a multicentre study. Rheumatol Int 1998;18:17-20.

2. Shagan BP, Friedman SA. Raynaud's phenomenon in hypothyroidism. Angiology 1976;27:19-25.

3. Sipila R, Viitasalo K, Keikkila J. Hypothyroidism, Raynaud's phenomenon, and acute myocardial infarction in a young woman. Clin Cardiol 1983;6:304-6.

4. Lateiwish AM, Feher J, Barackzka K, Racz K, Kiss R, Glaz E. Remission of Raynaud's phenomenon after L-thyroxine therapy in a patient with hypothyroidism. J Endocrinol Invest 1992;15:49-51.

5. Shagan BP, Friedman SA. Raynaud's phenomenon and thyroid deficiency. Arch Intern Med 1980;140:832-3.

6. Al-Deiri M, Benn JJ, Deighton CM. An unusual association with Raynaud's phenomenon. Rheumatology Oxford 2007;46:92-3.

J Rheumatol 2009;36:1; doi:10.3899/jrheum.080678 